\title{
User's satisfaction with information system quality: An empirical study on the hospital information systems in Ho Chi Minh City, Vietnam
}

\author{
Nguyen Tran Thuy Trang ${ }^{1 *}$, Nguyen Manh Tuan ${ }^{1}$ \\ ${ }^{1}$ Hochiminh City University of Technology - VNUHCM, Vietnam \\ "Corresponding author: nguyentranthuytrang@gmail.com
}

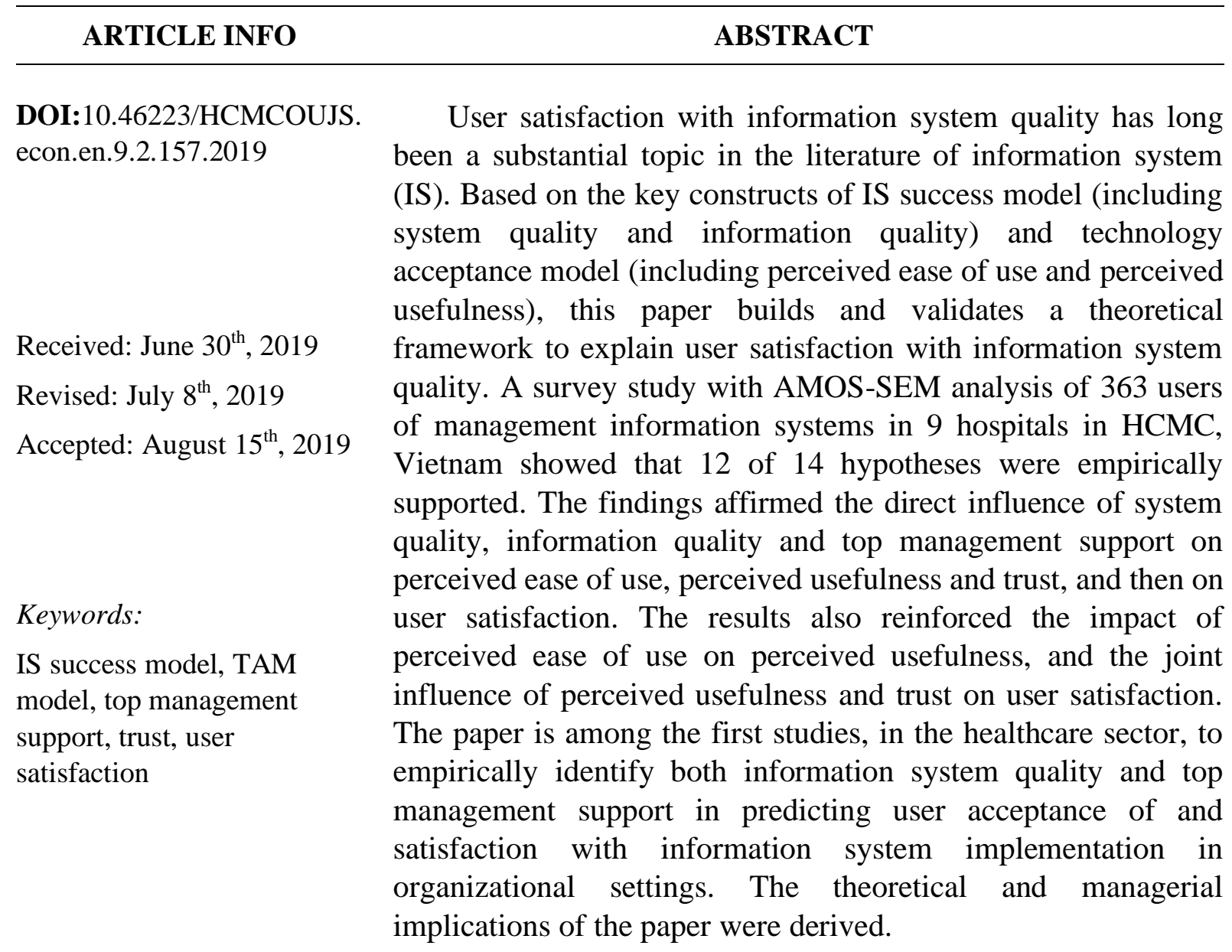

\section{Introduction}

Nowadays, worldwide, a new wave of technological and digital transformation is being strongly driven and described as the industrial revolution 4.0 in many industries. Healthcare has no difference. Big data will be created and will be available for machine learning and data analysis in the healthcare sector. This event is a strong fundamental to approach artificial intelligence in the future. This process can identify optimal hospital management. Besides that, the digital technology's application by the implementation of the Hospital Information System 
(HIS) brings huge benefits to the healthcare sector for healthcare providers, hospital employees, doctors, nurses, pharmacists, technicians, and others.

How about the trend of a digital transformation in Vietnam to adopt HIS in healthcare?

This trend is strong in many hospitals in Vietnam (VN). The Ministry of Health issued Decree No. 54 in 2017, including the criteria to apply the hospital information technology with the objectives to enhance the implementation of new technology in healthcare treatment and management to develop the smart hospital system in the future (CIMSI, 2019). Upon the criteria, Hospital Information Systems (HIS) will be implemented for a Vietnam healthcare system sometimes. VN Ministry of Health has issued the new circular on Mar 01, 2019, which requests all the 1st class hospitals implementing Electronic Health Record (EHR) from 2019 2023; other facilities should prepare to get ready for the technology; from 2024 - 2028, all healthcare system across the country must replace the paper-based medical record by the electronic one (Tuan Minh, 2019).

On the other hand, fast-moving in HIS applications in healthcare requires the users to catch up quickly HIS operational processes to maximize the benefits that HIS may bring. In this regard, user's acceptance and use of information system is the key element to the implementation's success, and furthermore, one of the important factors for system success is users' satisfaction when they employed the system (Oktal, Alpu, \& Yacizi, 2016).

Therefore, in the context of hospitals at Ho Chi Minh City, Vietnam, the main purpose of this study is to investigate the factors impacting on HIS user satisfaction and the relationships among those factors. We expect the findings of the current paper would bring significant theoretical and practical implications to enrich the valuable reference on HIS implementation in Ho Chi Minh city, Vietnam.

This paper is structured as follows. Theoretical framework and hypothesized model are presented followed by methods and findings on a measurement model and structural model, raising some theoretical implications and managerial implications.

\section{Theoretical framework and hypothesized model}

\subsection{Background}

Moghaddasi, Mohammadpour, Bouraghi, Azizi, and Mazaherilaghab (2018, p. 1) stated that "the Hospital Information System (HIS) is an integrated information system that provides hospital information requirements for daily operations such as planning and patient care". HIS is to manage the hospital operation including activities of medical, clinical, financial and administrative execution (Pai \& Huang, 2011). Back to 1970, HIS was developed basing on the integration of patient's diagnosis, clinical management, healthcare treatment and measurement so as to enhance hospital efficiency and effectiveness.

For HIS practice in Vietnam, a patient will be issued an own code at first-time hospital visiting. The different approaches during patient's clinical healthcare processes such as laboratory tests, X-ray, image diagnosis, treatment, medicine dispensing, payment and reimbursement then will be operated accordingly at laboratory information system (LIS), 
radiology information system (RIS), picture achieving communication system (PACS), electronic medical record system (EMR), pharmacy information system, financial information system and health insurance information system. Hospital employees include healthcare and nonhealthcare professionals can work with HIS. While healthcare professionals are doctors, pharmacists, nurses and technicians, non- healthcare professionals are staffs at finance, human resource, IT and administration departments. They know clearly that they will work on integrated systems inside the hospital. They will have the rights to access the systems under permission at their scope of work. For example, they can add patient information under their responsibility, or view laboratory patient's information, radiology patient's information or treatment information thanks to system integration of LIS, RIS, PACS, EMR and/or PIS.

$\mathrm{Vu}$, Nguyen, Webster, and Nimunkar (2011) explored that employees in the hospital will have the right to access HIS database by using their username and password. Every employee logs in to HIS will be responsible for all activities they have done in the system's database. The system will monitor any action on the data record from the user. The system will not allow the user to modify any previous information. Employees are allowed to add and view the patient's medical information on the database only. In Vietnam, researchers from the Ministry of Health have designed the Medisoft 2003 which has been known as HIS software implemented in many Vietnam hospitals until now.

On the other hand, IS success model (DeLone \& McLean, 1992) and Technology Acceptance Model (Davis, 1989) were the well-known conceptualizations in the literature of IS acceptance and use (Mohammadi, 2015). Oktal et al. (2016) recently demonstrated using these two theories to explore users' satisfaction with legal information systems in Turkey, or Pai and Huang (2011) successfully employed these both models for evaluating user's intention to use e-health systems in Taiwan. Hence, this study deliberately uses the two foundations as an organizing framework to investigate users' satisfaction with their HIS in HCMC, Vietnam.

\subsubsection{Information Systems Success Model (IS Success model)}

IS success model was first proposed by DeLone and McLean (1992). This is the prominent and well-known success theory in the information system which was widely cited in the literature with over 8,000 published citations according to Google Scholar so far (DeLone \& McLean, 2016). It should be noted that IS success model was impressive because it was clearly argued that the adoption of an IS does not necessarily indicate its success rather than a possible precursor for the system's success (DeLone \& McLean, 2016). In details, from the single user viewpoint, satisfaction with IS qualities could be a stable measure in the literature, which refers to the extent to which a user perceives a system to be valuable and deserves to use it again after his/her trial or first use (DeLone \& McLean, 2003). Furthermore, out of six dimensions of IS success, the three ones of qualities, namely system, information and service quality, were considered as the fundamental factors of IS success model (Rana, Dwivedi, Williams, \& Lal, 2015). However, we are not going to consider the dimension of service quality in our proposed research model. The reason for this decision is that, from an organization view, the service quality is mainly concerned with the quality of IT departments in response to the demands of the rest of the organization, rather than the quality of IS application (Petter, DeLone, 
\& McLean, 2008). Hence, in this paper, we employ the three key constructs of IS success model (including quality, information quality and user satisfaction) to investigate user acceptance and use of HIS applications.

\subsubsection{Technology Acceptance Model (TAM)}

TAM model first proposed by Davis (1989) is considered as the principal theory of individual user's acceptance and use of IT-based systems (King \& He, 2006). Thanks to its parsimoniousness and robustness, TAM became the most commonly employed model for evaluating the IS acceptance so far (Al-Emran, Mezhuyev, \& Kamaludin, 2018). One of the key advantages for TAM evolving into the leading model in the area is that it comprises two distinct belief of system users or most decisive factors of actual system use, which are perceived usefulness (PU) and perceived ease of use (PEOU) (Marangunic \& Granic, 2015). Therefore, we will adopt these two constructs in developing our research mode as explained below.

\subsubsection{Acceptance and success of hospital information systems}

Hospital information system research has become an attractive trend with the fact that many researchers were and are engaging to examine its acceptance and use by healthcare professionals and administrative staffs (Pai \& Huang, 2011). For example, in Nigeria, also a developing country, from a healthcare professional perspective, Zayyad and Toycan (2018) very recently conducted an investigation of factors affecting user adoption of e-health technology, using TAM as a conceptual framework. With the same direction of TAM based acceptance, Jaradat and Smadi (2013) examined the factors that influence user's behavioral intention of mobile healthcare information systems in 4 governmental hospitals in Jordan.

However, for e-health scholars in general, few of them paying attention to studying user's actual use of the system (Pai \& Huang, 2011), not mentioning to exploring users' satisfaction with the system after their initial use (e.g., Oktal et al., 2016). On the other hand, it should be noted that user satisfaction with prior usage of the system is the primary factor for sustained acceptance and use (Bhattacherjee \& Lin, 2015).

On the other hand, when exploiting IS as new technology applications in organizations, employees need to be supported by their managers, which has been long emphasized in, for example, Ein-Dor and Segev (1978). Furthermore, when dealing with IS in the organization, user trust was also one of the important determinants to determine user behavior and evaluations (for a meta-analysis, see, Wu, Zhao, Zhu, Tan, \& Zheng, 2011). In specific, user trust has risen in importance in the literature with the fact that more studies investigate its effects on system use (e.g., Oktal et al., 2016).

Therefore, this paper proposes a modified comprehensive model of IS success model and TAM model that incorporates the two important factors, namely top management support and trust, to predict and explain user satisfaction with IS qualities in the healthcare context in HCMC, Vietnam. 


\subsection{Perceived Ease of Use (PEoU)}

Zhou (2011) indicated that system quality affects mobile site user's judgment on the utility or difficulty in use. Users may be interrupted or delayed to approach the necessary information due to poor system quality which may cause the difficulty and inconvenience for users in their system use. Kim and Lennon (2013) pointed out that system quality includes the indicators of design quality, response time and accessibility at their study on users' behaviors in e-commerce. The design quality was described in system function and data transfer speed. The response time was mentioned in the time that the system needs to perform the feedback. The accessibility was identified as the extent of the system is accessible. High-speed accessibility to the system will increase the user's perceived ease of use. The mentioned above indicators of the system quality have significant impacts on the information system user's perceived ease of use (Pai \& Huang, 2011). Therefore, we suggest the following hypothesis:

\section{H1.1 System quality positively affects user's perceived ease of use.}

For information quality, Zhou (2011) studied on the mobile sites and claimed that users will realize difficulty to use the system if information quality is low, limited, obsolete, out of date or incorrect. Wixom and Todd (2005) determined that information quality affects the websites user's perceived ease of use. Thus, we propose the following hypothesis:

H2.1 Information quality positively affects user's perceived ease of use

\subsection{Perceived Usefulness (PU)}

For system quality, Cenfetelli, Benbasat, and Al-Natour (2008) stated that prompt of the system help to reduce users' effort spent on information search and improve their work and life effectiveness. Zhou (2011) examined that information system users may be interrupted to access the system if system quality is low, disadvantage or poor. The users may need to invest more time to obtain the necessary information due to the lack of efficient navigation. This inconvenience makes the users feel difficult to work continuing, therefore, it leads to a decrease in their PU. Some scholars (e.g., Pai \& Huang, 2011) described that the information system users realize the usefulness as they can get the relevant information that they need. Zhou (2011) also analyzed that system quality significantly affects user's perceived usefulness. Thus, the following hypothesis is proposed:

\section{H1.2 System quality positively affects user's perceived usefulness}

Next, for information quality of the system, DeLone and McLean (2003) clarified that system users discern usefulness of the system if the system information quality is high. They can retrieve the right and useful information that they need for their work. The information system can provide correct information with high accuracy (Pai \& Huang, 2011). The information system can provide updated information (Zhou, 2011). Besides, Wixom and Todd (2005) studied that information quality affects the user's perceived usefulness of web sites. Thus the research proposes the following hypothesis:

H2.2 Information quality positively affects user's perceived usefulness 


\subsection{Top management support}

Igbaria, Guimaraet, and Davis (1995) explored that top management support which includes top management encouragement and allocation of resources has positive impacts on perceived ease of use and perceived usefulness of users, and then on their trust in the relevant system operations. Thus, we propose the following hypotheses:

H3.1 Top management support positively affects user's perceived ease of use

H3.2 Top management support positively affects user's perceived usefulness

H3.3 Top management support positively affects user's trust

On the other hand, as the reliance of users on information system (Oktal et al., 2016), the trust could increase user's belief in maximizing the system's ability and integrity to achieve user performance in their work (Gefen, Karahanna, \& Straub, 2003). The users expect to employ information system and trust guarantees that the users can get useful results and good outcomes in their system operations. The effect of trust on the user's perceived usefulness has been identified in previous studies (e.g., Yoon, 2009). Therefore, the following hypothesis is recommended:

H4. Trust positively affects user's perceived usefulness

Mathieson (1991) stated that users' perceived ease of use affects positively users' perceived usefulness in the use of word processing software. Moreover, almost all studies that adopted TAM claimed that the user's PEoU positively affects the user's PU (Pai \& Huang, 2011). Thus, we suggest the following hypothesis:

\section{H5. Perceived ease of use positively affects user's perceived usefulness}

\subsection{Trust}

Zhou (2011) agreed that both system quality and information quality of information system has impacted user's trust as indicated in previous studies. The same argument was found in, for example, Vance, Christophe, and Straub (2008). Therefore, the following hypotheses are proposed:

H1.3 System quality positively affects user's trust

\subsection{Satisfaction}

In the scope of e-commerce research, DeLone and McLean (2004) mentioned that satisfaction is an important factor in the information systems success model. In general, satisfaction shows a gap between users' expectation and their perceived performance. Users will be satisfied if outcomes are better than expected. For example, users always look and wait for ease of use, usefulness, and trustworthiness of the system. Hence, they can get satisfaction if these factors are met.

Oktal et al. (2016) determined that indicators of PU as work efficiency acquired the necessary information, workload decrement, process speed increment all impact significantly on user satisfaction. In the same vein, Zhou (2011) studied that all of the perceived usefulness, 
perceived ease of use and user's trust significantly affect user satisfaction. Thus, we come to the following hypotheses:

H6. Perceived usefulness positively affects user's satisfaction

H7. Perceived ease of use positively affects user's satisfaction

H8. Trust positively affects user's satisfaction

\section{Methods}

\subsection{Survey administration}

The survey informants adopted are both healthcare and non-healthcare professionals, which are end-users of HIS. While the former professionals include doctors, nurses, pharmacists and technicians working at medical departments of hospitals, the latter professionals include administrators working at hospital departments of community service, customer care, finance department, information technology department, general planning department and quality management.

The questionnaires were delivered to these professionals of 9 hospitals in HCMC including 34 different departments. A total response of 407 was collected by the time the 2 month survey was ended. The removal of the questionnaires of excessive missing information resulted in 363 valid responses for further analysis. Of the entire valid sample, $64 \%$ were female; $10 \%$ were under 25 years old, 54\% between 25 and 34 years old, 24\% between 35 and 44 years old and the rest from 45 years old; $80 \%$ were healthcare staff members and $20 \%$ administrative staff members; $88.4 \%$ were employees and $11.6 \%$ officers of management levels; $55 \%$ were university level of education and above and $45 \%$ college and others; and finally $38 \%$ were of under 5 years of working, $44 \%$ from 5 to 14 years of working and the rest of 15 years of working and above.

\subsection{Measurement}

All measurement items of theoretical constructs are adapted from previous studies and pretested using four doctors in four different hospitals to check the ease of understanding and relevance of questionnaires. A five-point Likert-type scale was adopted ranging from 1 as completely disagreed to 5 as completely agreed.

To measure system quality and information quality, we used five-item scales developed by Pai and Huang (2011), Zhou (2011), DeLone and McLean (2003), Zhou (2011), and Oktal et al. (2016) respectively. Top management support were assessed with items based on Igbaria et al. (1995), trust on Oktal et al. (2016), both perceived ease of use and perceived usefulness on Zhou (2011) and Oktal et al. (2016), and finally, user satisfaction, on Oktal et al. (2016) and Zhou (2011).

\subsection{Data analysis}

Obtained data after the questionnaire's collection then be loaded in an excel sheet for later data analysis applied Anderson and Gerbing (1988)'s two-step SEM approach using SPSS/ 
AMOS 20.0. First, SPSS 20.0 helps to test the reliability and validity preliminarily by Cronbach's alpha and Explore Factor Analysis. The next step, SEM technique with AMOS 20.0 is used to reconfirm the measurement model and structural model using Confirmatory Factor Analysis (CFA) and SEM analysis.

\section{Findings}

\subsection{Measurement model}

In preliminary testing, all measurement scales showed reliability with Cronbach's alpha - $\alpha>0.6$. Then, after Explore Factor Analysis (EFA), items with factor loading under the threshold of 0.5 will be eliminated leading to the removal of five items. Next, the remaining scales were analyzed by CFA. Refinement is the outcome of unsatisfied items due to high MI with many other items. After this refinement, there were six items eliminated.

The CFA results of refined measurement model indicated good model fit indices with CMIN/df = $2.012(<3)$, Goodness-of-fit index GFI = $0.911(>0.9)$, Adjusted Goodness-of-fit index AGFI $=0.883(>0.8)$, Tucker-Lewis index TLI = $0.953(>0.9)$, Incremental-fit index $\mathrm{IFI}=0.961(>0.9)$, Comparative fit index CFI $=0.961(>0.9)$ and Root mean square error of approximation RMSEA $=0.053(<0.08)$. The satisfactory model fit asserted that the measurement model fits the data in the empirical study.

The composite reliability (CR) was in a range of 0.782 to 0.906 , reconfirming the construct reliability. Besides that, the average variance extracted (AVEs) value ranged from 0.549 to $0.706(>0.5)$ and all standardized factor loadings ranged from 0.673 to $0.898(>0.5)$ with significant $\mathrm{p}$-value, indicating the convergent validity of the constructs (Table 1). The discriminant validity was acceptable when the square roots of AVEs are greater than the correlation of two latent variables, showing the achieved discriminant validity (Table 2). Briefly, Tables $1 \& 2$ illustrated that the proposed measurement research model fits with the empirical data in the study.

\section{Table 1}

The convergent validity of the constructs

Construct - Reliability ( $\alpha$ \& CR)

items - Convergent validity (AVE \& standardized factor loading)

Standardized

$p$

Satisfaction $(S A T)(\alpha=0.934, C R=0.906, A V E=0.706)$

SAT1 I satisfied because the $\mathrm{X}$ information system can help me in fulfillment of needs in my work.

0.827

0.875

0.848

0.810 work.

$\begin{array}{ll}\text { SAT2 } & \text { I satisfied because of the } X \\ \text { SAT3 } & \text { I like to use the X system. }\end{array}$

SAT4 I think the X system is worthy to be deployed for my 
Construct - Reliability ( $\alpha$ \& CR)

items - Convergent validity (AVE \& standardized factor loading)

Standardized

factor loading

Information quality (INFOQ) $(\alpha=0.859, \mathrm{CR}=0.859, \mathrm{AVE}=0.549)$

INFOQ1 The information which I can retrieve from the $\mathrm{X}$ system is

$\begin{array}{ll} & \text { necessary and useful for my work. } \\ \text { INFOQ2 The X system can provide correct information with high }\end{array}$

INFOQ3 The $\mathrm{X}$ system can provide updated information on time.

$0.723 \quad * * *$

The content of information that I obtained from the $\mathrm{X}$

INFOQ4 system is easy for understanding.

significant

0.743

INFOQ5 The information which I get from the X system has high relevance.

$0.785 \quad * * *$

Trust (TRUST) $(\alpha=0.893, C R=0.782, A V E=0.643)$

TRUS1 I believe the X system can prevent the info leakage effectively

TRUS2 I believe the X system can prevent unauthorized access.

System quality (SYSQ) $(\alpha=0.852, C R=0.873, A V E=0.7)$

SYSQ2 The $\mathrm{X}$ hospital information system has high speed access.

SYSQ3 The X hospital information system has high data transfer speed

SYSQ4 I can quickly perform operations that I need on the X

$0.812 \quad * * *$

$0.791 \quad$ significant

$0.898 \quad * * *$

0.917

$0.673 \quad * * *$

Top management support (TOPMS) $(\alpha=0.848, C R=0.839, A V E=0.634)$

TOPMS2 I am always supported and encouraged by my boss to use $\quad 0.781$ the

TOPMS3 $\begin{aligned} & \text { X system in the performance of my job. } \\ & \text { TOPMS4 } \\ & \text { Management has provided most of the necessary help and } \\ & \text { resources to get me used to the X system quickly. }\end{aligned}$
Perceived usefulness $(P \boldsymbol{U})(\boldsymbol{\alpha}=\mathbf{0 . 9 0 7 ,} \boldsymbol{C R}=\mathbf{0 . 8 9 2}, \boldsymbol{A} \boldsymbol{V E}=\mathbf{0 . 6 7 5})$

$0.774 \quad$ significant

$0.833 \quad * * *$

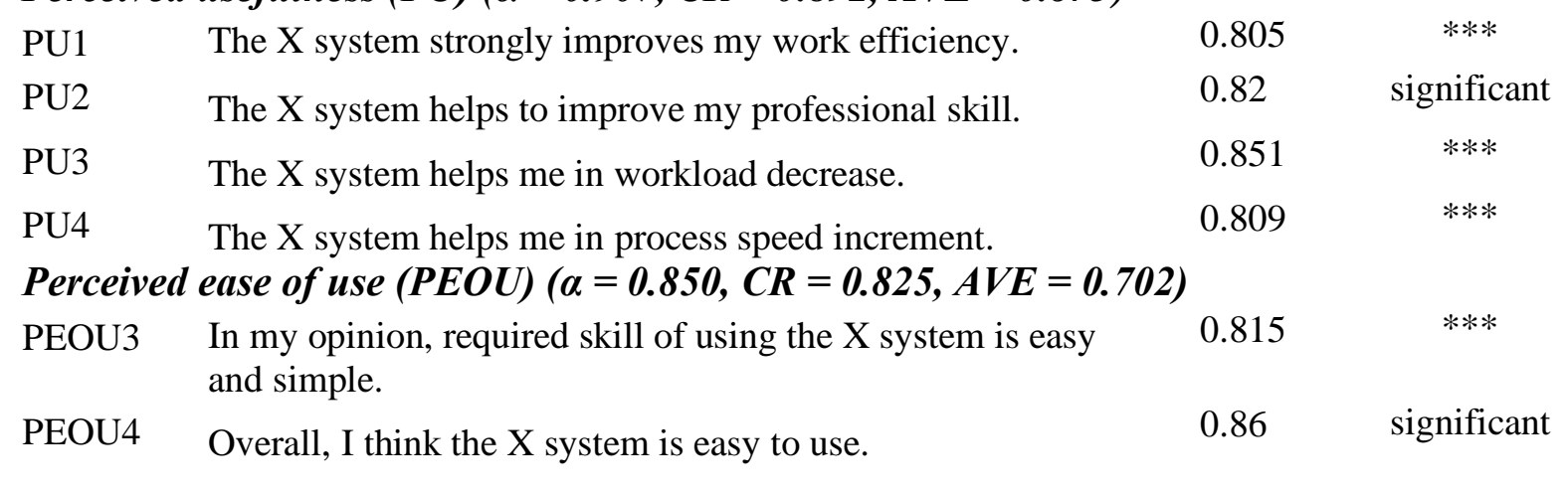

Note: $* \mathrm{p}<0.05,{ }^{* *}: \mathrm{p}<0.01$ and ${ }^{* * *}: \mathrm{p}<0.001 ; \alpha$ : cronbach's alpha; CR: composite reliability; AVE: average variance extracted

Source: Data analysis result of the research 


\section{Table 2}

Discriminant validity

\begin{tabular}{|l|l|c|c|c|c|c|c|}
\hline Constructs & SAT & INFOQ & TRUST & SYSQ & TOPMS & PU & PEOU \\
\hline SAT & 0.84 & & & & & & \\
\hline INFOQ & 0.68 & 0.74 & & & & & \\
\hline TRUST & 0.63 & 0.64 & 0.80 & & & & \\
\hline SYSQ & 0.62 & 0.60 & 0.53 & 0.84 & & & \\
\hline TOPMS & 0.70 & 0.66 & 0.67 & 0.48 & 0.80 & & \\
\hline PU & 0.82 & 0.72 & 0.58 & 0.64 & 0.67 & 0.82 & \\
\hline PEOU & 0.64 & 0.59 & 0.52 & 0.50 & 0.66 & 0.70 & 0.84 \\
\hline
\end{tabular}

Note: diagonal elements (in italic) are square root of average variance extracted - AVE

Source: Data analysis result of the research

\subsection{Structural model}

The SEM test result of the proposed hypotheses indicated the good fit model indices: Chi-square $/ \mathrm{df}=2.015(<3), \mathrm{AGFI}=0.883(>0.8), \mathrm{GFI}=0.910, \mathrm{TLI}=0.953, \mathrm{IFI}=0.960, \mathrm{CFI}$ $=0.960$ (all greater than 0.9) and RMSEA $=0.053(<0.08)$. (Figure 1). Out of all of 14 tested hypotheses, two hypotheses are not supported (H4 and H7).

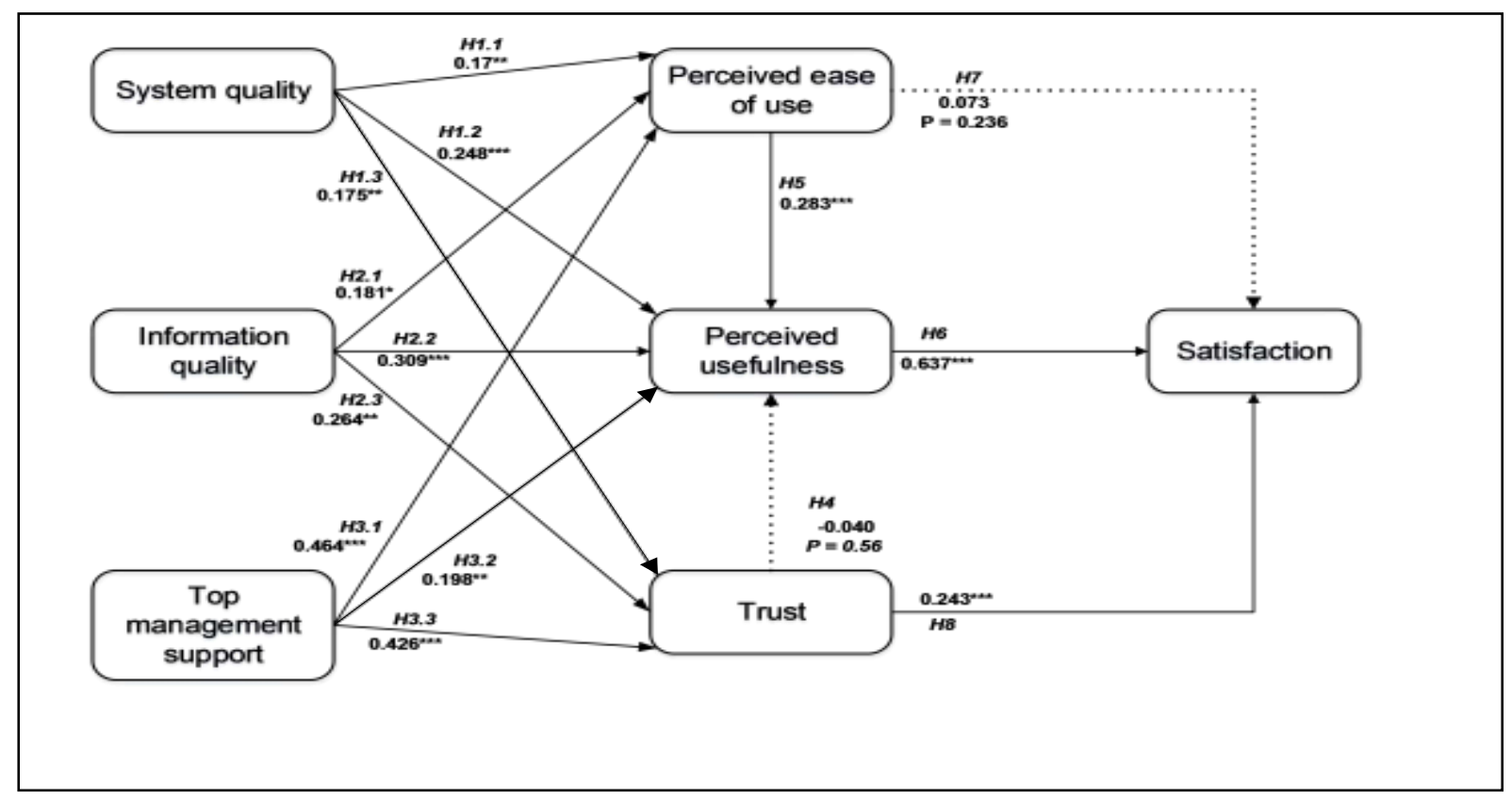

Figure 1. Testing results of structural model 


\section{Conclusion}

\subsection{Discussion}

5.1.1. Dependent factor group: perceived ease of use, perceived usefulness, trust, and satisfaction

Among three factors of perceived ease of use, perceived usefulness and trust, the empirical study findings strongly indicate that perceived usefulness has the strongest impact on satisfaction ( $\beta=0.637)$. This outcome significantly reconfirms Zhou's (2011) work on mobile website adoption.

The second factor "perceived ease of use" showed no impact on HIS user's satisfaction (H7 unsupported). Two reasons that may help to explain this non-supported hypothesis are respondent characteristics and research context. First, there are some remarkable different characteristics of the respondents on the education level in this research alongside informant characteristics in the literature review leading to the unsupported hypothesis. Second, regarding the research context, this empirical study is designed ten years after the Zhou's in 2011. The research is processed in the internet of things (IOT) disruption and industry 4.0 with a strong digital transformation trend in many Vietnam organizations leading to IS familiarity in daily working. Thus, "HIS ease of use" is unimportant in this context. One more significant point that the author mentioned in the background context in the introduction, the healthcare system is changing from very disadvantage and complicated paper charts system to HIS with the software technology platform that shows huge benefits and advantages. At the first time of HIS installation and use, employees may perceive benefits and impressed on good results from HIS contribution. Thereby, whether ease of use or not, they would still be satisfactory.

However, although the role of factor "perceived ease of use" is not a major concern to gain HIS user's satisfaction, it still contributes importantly to gain HIS user's perceived usefulness. So, to some extent, "perceived ease of use" may contribute to gain HIS user's satisfaction indirectly through the construct of "perceived usefulness".

The supported hypothesis H5 on the impact of perceived ease of use on perceived usefulness shows the same finding with the previous studies such as Oktal et al. (2016)'s. Next, the hypothesis H8 explicitly proves that HIS user's trust positively impacts on their satisfaction, which was also identified previously in Zhou (2011).

The hypothesis H4 resulted in an insignificant link between trust and user's perceived usefulness (H4 unsupported). This unsupported relationship may be explained to the fact that user trust would be more of affective feeling whereas perceived usefulness would be more of cognitive evaluation resulting from user experience with the system actualoperation.

Finally, it should be noted that, with the supported hypothesis H3.1, in comparison to system quality and information quality, top management support is the strongest predictor for perceived ease of use (highest path estimate $\beta=0.464$ ). 


\subsubsection{Independent factor group: system quality, information quality, top management} support

The authors would like to explore which independent factor among "system quality", "information quality", "top management support" that has the strongest influence on the three dependent factors of user's "perceived ease of use", "perceived usefulness" and "trust". The interesting findings are that top management support has a strong impact on perceived ease of use and trust; information quality has a strong impact on perceived usefulness.

The supported hypothesis H1.1, of the impact of system quality on perceived ease of use ( $\beta=0.169)$, has confirmed the previous study findings from Pai and Huang's (2011) work on HIS. Next, the supported hypothesis H1.2, of the influence of system quality on perceived usefulness $(\beta=0.248)$, helps to reinforce the finding of Zhou's (2011) paper on the mobile website system. The hypothesis of H1.3 on system quality impacting user's trust" ( $\beta=0.175)$ may indicate the understanding similar to exploration from Zhou (2011) and Vance et al. (2008).

The supported hypothesis $\mathrm{H} 2.1$, of the influence of information quality on perceived ease of use $(\beta=0.181)$, validates that hospital employees realizing the difficulty in using HIS when its information quality is low, limited, obsolete, out of date or incorrect, discernibly.

On the other hand, the supported hypothesis H2.2 $(\beta=0.309)$, as discussed above, may bring an interesting finding with the fact that, in comparison to system quality and top management support, information quality has the strongest impact on perceived usefulness. This is in line with the findings from Wixom and Todd (2005), and Zhou (2011).

The supported hypothesis $\mathrm{H} 2.3$, of the influence of information quality trust $(\beta=0.264)$, leads to the same finding with Zhou (2011)'s.

Moreover, there is an interesting finding with the fact that top management support has the largest influence on perceived ease of use and to trust compared to system quality and information quality. Top management support contributes important role to build up HIS user's perceived ease of use and trust as well as build up their reliance on HIS use, leading to HIS user's acceptance to use the system to perform the HIS implementation's success and avoid user's resistance. The supported hypotheses $\mathrm{H} 3.1$ and H3.2, of the impact of top management support on perceived ease of use and usefulness respectively, impressively confirm the previous findings from Igbaria et al. (1995).

Finally, our model successfully validates the expected significant relationship between top management support and user's trust (H3.2 supported), which may reinforce the substantial role of top management support in HIS implementation to enhance employee's perception of trust and next, of satisfaction.

\subsection{Theoretical implications}

The study shows four theoretical implications to the IS literature from the user's viewpoint. First, this research asserts the role of the user's perceived usefulness and user's trust as predictors on the user's satisfaction, which has been indicated in Zhou's (2011). 
Second, the significant role of the user's trust in our model may also indicate an insightful addition to Pai and Huang's (2011) and Igbaria et al.'s (1995) publications whereby trust has notbeen studied yet in explaining user's satisfaction.

Third, the strong impact of top management support on the user's trust revealed a useful link in understanding user acceptance and satisfaction. This would be a worthy complement to, for example, the widely-cited work of Igbaria et al. (1995) on IT usage in work settings.

Finally, this research may provide one more of evidence in the literature on the simultaneous effects of IS qualities and top management support perceived by users to user satisfaction through perceived ease of use, perceived usefulness and trust. This integration may be valuable as it emphasizes on both system (IS quality) and management (top management support) factors in explanation of user satisfaction with HIS implementation.

\subsection{Managerial implications}

As mentioned previously, Vietnam Ministry of Health has issued Decree No. 54 in 2017, including instructions and guidelines to apply information technology in hospitals with the aim of strengthening the deployment of new technology in management and healthcare services for the development of future smart hospital systems (CIMSI, 2019). According to the decree, the technology system platform of HIS such as Healthcare Information System, Laboratory Information System, Picture Achieving Communication System, Electronic Medical Record and Electronic Health Record (EHR), and so on will be processed in the next coming years. The governmental new circular requests that hospitals of the first level in the national system need to apply EHR from 2019 to 2023, and that the other ones would be ready for the next period between 2024 and 2028, and moreover, during the time, all healthcare entities and bodies must change from the paper-based work systems to the IT-based ones (Tuan Minh, 2019).

This study provides valuable knowledge to making certain for a favorable outcome of HIS progress for hospital management boards and managers. Knowledge gained from the causal relationship between related factors and the user's satisfaction in the study will give meaningful recommendations for hospital management boards and managers to evaluate and analyze the situation in hospitals where they are leading and managing. After that, they can make the right decisions and actions on HIS operation, which may improve hospital development in short and long terms.

The research findings strongly recommend the hospital managers should take action to gain the employee's satisfaction on HIS use because satisfaction is the key component in the structural model. It reflects the relationship with all the remaining components directly or indirectly.

In order to have an employee's satisfaction with HIS use, the management boards must shape the user's perceptions of usefulness and trust, especially usefulness. Besides, the perceived ease of use also indirectly, but positively, affects satisfaction. The hospital management boards need to facilitate HIS system quality to make sure that HIS will bring benefits to the user. Especially, they should focus on, for example, the high data transfer speed of the system, one of the most powerful indicators of HIS system quality. 
Besides system quality, the management boards need to make decisions to increase HIS information quality to ensure that HIS can provide necessary and useful information, accurate information, or updated information timely and relevant content for user's daily practice and work. It should be noted that HIS information quality has a strong impact on the user's perceived usefulness.

One of the interesting results that need to be noticed by the management board is that top management support is of paramount importance in building up user's trust and perceived ease of use. Thereby, management heads should participate in resources allocation for HIS users, and encourage hospital employees to use HIS for their job performance. Management heads can also provide the necessary help and resources to get employees to employ HIS quickly. They should show their enthusiasm to see the staff's happiness in using HIS.

\subsection{Limitations and further research}

The research has some limitations. First, convenient sampling and samples are situated in Ho Chi Minh City, not representing the population of HIS throughout the country. This may suggest some future research on HIS in other provinces and further, even on IS in other industries such as finance, bank, education, etc. Second, in explaining user satisfaction, the role of culture may be necessary (e.g., Vance et al., 2008), and hence, the antecedents of organizational cultures would deserve to be included in future studies. Third, the differences between the hospital departments and between the hospitals have not been analyzed yet. This limitation opens venues for future works that may bring more theoretical and practical implications for the healthcare sector.

\subsection{Concluding remarks}

Conclusively, the research findings may be helpful to provide a sharply understanding of the determinants of the user's satisfaction and more, the decisive factors may influence these determinants.

We can gain fruitful insights into the integration of HIS quality like system quality and information quality, as well as into human participation such as top management support in the relationship with user perception of usefulness, eases of use and trust.

In order to gain HIS user's satisfaction, the hospital managers should cumulate and build up the user's perceived usefulness and trust by paying attention and take appropriate actions and decisions to HIS quality and top management support's role. One of the most important factors that can be positively impacted and got benefits from mentioned actions is HIS user's perceived usefulness. Thereby, users will acquire the benefits through work efficiency improvement, professional skill improvement, process speed increase and, especially, workload decrease in daily practice and working in hospitals. These advantages obviously help HIS users to be willing to accept HIS, leading to HIS success in operation and avoid user's resistance to HIS use. This finding may be useful for hospitals to increase their competitive advantages. 


\section{References}

Al-Emran, M., Mezhuyev, V., \& Kamaludin, A. (2018). Technology acceptance model in M-learning context: A systematic review. Computers \& Education, 125, 389-412. doi:10.1016/j.compedu.2018.06.008

Anderson, J. C., \& Gerbing, D. W. (1988). Structural equation modeling in practice: A review and recommended two-step approach. Psychological Bulletin, 103(3), 411-423.

Bhattacherjee, A., \& Lin, C.-P. (2015). A unified model of IT continuance: Three complementary perspectives and crossover effects. European Journal of Information Systems, 24(4), 364-373. doi:10.1057/ejis.2013.36

Cenfetelli, R. T., Benbasat, I., \& Al-Natour, S. (2008). Addressing the what and how of online services: Positioning supporting - Services functionality and service quality for business-to-consumer success. Information Systems Research, 19(2), 161-181.

CIMSI. (2019). Retrieved June 30, 2019, from https://cimsi.org.vn/

Davis, F. D. (1989). Perceived usefulness, perceived ease of use, and user acceptance of information technology. MIS Quarterly, 13(3), 318-346. doi:10.2307/249008

DeLone, W. H., \& McLean, E. R. (1992). Information systems success: The quest for the dependent variable. Information System Research, 3(1), 60-95. doi:10.1287/isre.3.1.60

DeLone, W. H., \& McLean, E. R. (2003). The DeLone and McLean model of information systems success: A ten-year update. Journal of Management Information Systems, 19(4), 9-30. doi:10.1080/07421222.2003.11045748

DeLone, W. H., \& McLean, E. R. (2004). Measuring e-Commerce success: Applying the DeLone \& McLean information systems success model. International Journal of Electronic Commerce, 9(1), 31-47. doi:10.1080/10864415.2004.11044317

DeLone, W. H., \& McLean, E. R. (2016). Information systems success measurement. Foundations and Trends in Information Systems, 2(1), 1-16. doi:10.1561/2900000005

Ein-Dor, P., \& Segev, E. (1978). Organizational context and the success of management information systems. Management Science, 24(10), 1064-1077.

Gefen, D., Karahanna, E., \& Straub, D. W. (2003). Trust and TAM in online shopping: An integrated model. MIS Quarterly, 27(1), 51-90. doi:10.2307/30036519

Hair, J. F., Black, W. C., Babin, B. J., \& Anderson, R. E. (2014). Multivariate data analysis. Harlow, UK: Pearson Education Limited.

Hsiao, J. L., \& Chang, I. C. (2005). An empirical study of establishing nursing care plan systems. Journal of Information Management, 12(2), 27-43.

Igbaria, M., Guimaraes, T., \& Davis, G. B. (1995). Testing the determinants of microcomputer usage via a structural equation model. Journal of Management Information Systems, 11(4), 87-114. 
Jaradat, M.-I. R., \& Smadi, Z. M. A. (2013). Applying the technology acceptance model to the introduction of mobile healthcare information systems. International Journal of Behavioural and Healthcare Research, 4(2), 123-143. doi:10.1504/IJBHR.2013.057363

Kim, J., \& Lennon, S. J. (2013). Effects of reputation and website quality on online consumers' emotion, perceived risk and purchase intention. Journal of Research in Interactive Marketing, 7(1), 33-56. doi:10.1108/17505931311316734

King, W. R., \& He, J. (2006). A meta-analysis of the technology acceptance model. Information and Management, 43(6), 740-755. doi:10.1016/j.im.2006.05.003

Marangunic, N., \& Granic, A. (2015). Technology acceptance model: A literature review from 1986 to 2013. Universal Access in the Information Society, 14(1), 88-95. doi:10.1007/s10209-014-0348-1

Mathieson, K. (1991). Predicting user intentions: Comparing the technology acceptance model with the theory of planned behavior. Information Systems Research, 2(3), 173191. doi:10.1287/isre.2.3.173

Moghaddasi, H., Mohammadpour, A., Bouraghi, H., Azizi, A., \& Mazaherilaghab, H. (2018). Hospital Information Systems: The status and approaches in selected countries of the Middle East. Electronic Physician, 10(5), 6829-6835. doi:10.19082/6829

Mohammadi, H. (2015). Investigating users' perspectives on e-learning: An integration of TAM and IS success model. Computers in Human Behavior, 45(1), 359-374. doi:10.1016/j.chb.2014.07.044

Oktal, O., Alpu, O., \& Yacizi, B. (2016). Measurement of internal user satisfaction and acceptance of the e-justice system in Turkey. Aslib Journal of Information Management, 68(6), 716-735. doi:10.1108/AJIM-04-2016-0048

Pai, Y. F., \& Huang, K. I. (2011). Applying the technology acceptance model to the introduction of healthcare information systems. Technological Forecasting \& Social Change, 78(4), 650-660. doi:10.1016/j.techfore.2010.11.007

Petter, S., DeLone, W., \& McLean, E. (2008). Measuring information systems success: Models, dimensions, measures, and interrelationships. European Journal of Information Systems, 17(3), 236-263.

Rana, N. P., Dwivedi, Y. K., Williams, M. D., \& Lal, B. (2015). Examining the success of the online public grievance redressal systems: An extension of the IS success model. Information Systems Management, 32(1), 39-59. doi:10.1080/10580530.2015.983019

Tuan Minh (2019). Vietnam to apply electronic health records from March 1. Health \& Education, Hanoi times. Retrieved August 10, 2019, from http://www.hanoitimes.vn/ health-education/2019/02/81e0d31c/vietnam-to-apply-electronic-health-recordsfrom-march-1/ 
Vance, A., Christophe, E. D. C., \& Straub, D. W. (2008). Examining trust in information technology artifacts: The effects of system quality and culture. Journal of Management Information Systems, 24(4), 73-100. doi:10.2753/MIS0742-1222240403

Vu, H. D., Nguyen, T. D., Webster, J. G., \& Nimunkar, A. J. (2011). A web-based electronic medical records and hospital information system for developing countries. Journal of Health Informatics in Developing Countries, 5(1), 155-170.

Wixom, B. H., \& Todd, P. A. (2005). A theoretical integration of user satisfaction and technology acceptance. Information Systems Research, 16(1), 85-102. doi:10.1287/isre. 1050.0042

Wu, K., Zhao, Y., Zhu, Q., Tan, X., \& Zheng, H. (2011). A meta-analysis of the impact of trust on technology acceptance model: Investigation of moderating influence of subject and context type. International Journal of Information Management, 31(6), 572-581. doi:10.1016/j.ijinfomgt.2011.03.004

Yoon, C. (2009). The effects of national culture values on consumer acceptance of ecommerce: Online shoppers in China. Information \& Management, 46(5), 294-301. doi:10.1016/j.im.2009.06.001

Zayyad, M. A., \& Toycan, M. (2018). Factors affecting sustainable adoption of e-health technology in developing countries: An exploratory survey of Nigerian hospitals from the perspective of healthcare professionals. Peer J, 6(6), 1-15. doi:10.7717/peerj.4436

Zhou, T. (2011). Examining the critical success factors of mobile website adoption. Online Information Review, 35(4), 636-652. doi:10.1108/14684521111161972 